\title{
Triterpenic Derivatives of Achillea alexandri-regis BORNM. \& RUDSKI
}

\author{
Tatjana Kundakovic, ${ }^{a, b}$ Nikolas Fokialakis, ${ }^{b}$ Prokopios Magiatis, ${ }^{b}$ Nada Kovacevic, ${ }^{a}$ and \\ Ioanna CHINOU*,b \\ ${ }^{a}$ Department of Pharmacognosy, Faculty of Pharmacy, University of Belgrade; Vojvode Stepe 450, 11000 Belgrade, \\ Serbia: and ${ }^{b}$ Division of Pharmacognosy and Chemistry of Natural Products, School of Pharmacy, University of Athens; \\ Panepistimiopolis Zografou, GR 15771 Athens, Greece. Received April 5, 2004; accepted July 15, 2004
}

Investigation of the aerial parts of Achillea alexandri-regis led to the identification of 19 chemical constituents: twelve 3-O-fatty acid esters of triterpene alcohols arnidiol (1-4), maniladiol (5-8) and $16 \beta$-hydroxylupeol (9-12), $\alpha$-amyrin, $\beta$-amyrin, $\beta$-sitosterol, 3,4- $O$-dicaffeoyl quinic acid, cinnamic acid, pinoresinol- $\beta$-D-glucoside and rutin. Among them, compounds 3, 4, 8, 11 and 12 are new natural products. The structures of all compounds have been elucidated on the basis of their spectral and chemical data.

Key words Achillea alexandri-regis; Asteraceae; triterpenic derivative

Aerial parts from different species of the genus Achillea have been used in traditional and modern medicine as bitter aromatics, astringents, chemostyptics, choleretics and

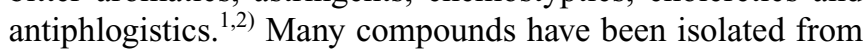
Achillea species, including flavonoids, sesquiterpene lactones and polyacetylenes. ${ }^{3)}$ Achillea alexandri-regis BorNM. \& RUDSKI is a stenoendemic species of Serbian Flora, ${ }^{4)}$ found only on Mount Ošljak in the northern branches of the Šara mountain range (southern Serbia). The extracts of this plant showed dose dependent anti-inflammatory and gastroprotective effects, as well as antioxidant activity. ${ }^{5,6)}$ A previous phytochemical study concerned only the composition of the essential oil. ${ }^{7)}$ Thus, we investigated the chemical composition of the extracts of the aerial parts of the plant.

The investigation of the combined chloroform and ethyl acetate extracts led to the identification of 15 chemical constituents: twelve 3-O-fatty acid esters of triterpene alcohols arnidiol (1-4), maniladiol (5-8) and 16 $\beta$-hydroxylupeol $(9-12), \alpha$-amyrin, $\beta$-amyrin ${ }^{8)}$ and $\beta$-sitosterol. ${ }^{9)}$

Compound 2 was obtained as a colorless powder. The ${ }^{1} \mathrm{H}-\mathrm{NMR}$ spectrum (Table 1) exhibited two characteristic peaks at $\delta 4.63$ and 4.65 corresponding to an exomethylene group, one doublet of doublets at $\delta 4.48$ and one doublet of doublets at $\delta 3.39$, revealing the presence of one esterified and one hydroxylated methine protons, and several overlapped signals between $\delta 0.85$ and 2.29 . The ${ }^{13} \mathrm{C}$-NMR spectrum (Table 1) showed the presence of two oxygenated $(\delta 77.33,80.49)$, two olefinic, and one esteric carbonyl $(\delta 173.73)$ and several aliphatic carbons. Alkaline hydrolysis of 2 afforded a triterpene diol and a fatty acid. The fatty acid was esterified with methanol and analyzed as a methyl ester using GC-MS and identified as palmitic acid. The triterpene diol was identified as arnidiol after interpretation of its MS and NMR spectra and by comparison with the reported spectroscopic data. ${ }^{10)}$ The position of the palmitic acid residue was elucidated by the Heteronuclear Multi Bond Correlation (HMBC) spectrum. The proton of the esterified position at $\delta 4.48(\mathrm{H}-3)$ was correlated with the esteric carbonyl carbon at $\delta 173.73$ and with the two characteristic methyl groups at $\delta 27.93$ and $16.54\left(\mathrm{CH}_{3}-23\right.$ and $\left.\mathrm{CH}_{3}-24\right)$; thus palmitic acid was linked at 3-OH of arnidiol through an ester bond.

Careful study of the above described GC-MS analysis revealed the presence of some fatty acid esters with different chain lengths. This observation led us to investigate the combined fractions adjacent to fraction of $\mathbf{2}$, and to isolate compounds 1,3 and 4 in addition to compound 2 . The ${ }^{1} \mathrm{H}-$ and ${ }^{13} \mathrm{C}$-NMR spectra of these fractions were similar to those of 2. Alkaline hydrolysis of the fractions containing 1-4 afforded arnidiol and a mixture of fatty acids, identified after esterification, as myristic acid, palmitic acid, stearic acid and eicosanoic acid.

Compound $\mathbf{6}$ was also obtained as a colorless powder. The ${ }^{1} \mathrm{H}-\mathrm{NMR}$ spectrum of $\mathbf{6}$ exhibited one characteristic triplet at $\delta 5.24$ corresponding to an olefinic proton, one doublet of doublets at $\delta 4.50$ and one doublet of doublets at $\delta 4.20$, revealing the presence of one esterified and one hydroxylated methine proton and several overlapped signals between $\delta 0.87$ and 2.29. The ${ }^{13} \mathrm{C}$-NMR spectrum of 6 showed the presence of two oxygenated $(\delta 65.97,80.45)$, two olefinic, and one esteric carbonyl and several aliphatic carbons. Alkaline hydrolysis of the isolated compound afforded a triterpene diol and a fatty acid. As previously mentioned, the fatty acid after esterification with methanol was analyzed as a methyl ester using GC-MS and was found to be palmitic acid. The triterpene diol was identified as maniladiol after interpretation of its MS and NMR spectra, and by comparison with the literature data. ${ }^{11)}$ The position of the fatty acid residue was elucidated by the HMBC spectrum as described for compound 2.

In addition to compound $\mathbf{6}$, the combined adjacent fractions led to the isolation of compounds $\mathbf{5}, \mathbf{7}$, and $\mathbf{8}$. The ${ }^{1} \mathrm{H}$ - and ${ }^{13} \mathrm{C}$-NMR spectra of the mixture were very similar to those of $\mathbf{6}$, and the alkaline hydrolysis of the fractions containing 5-8 afforded maniladiol and a mixture of fatty acids. After esterification, they were identified as myristic acid, palmitic acid, stearic acid and eicosanoic acid.

Compound $\mathbf{1 0}$ was obtained as a colorless powder. The ${ }^{1} \mathrm{H}-\mathrm{NMR}$ spectrum of $\mathbf{1 0}$ exhibited two characteristic doublets at $\delta 4.68$ and 4.57 , corresponding to an exomethylene group, one doublet of doublets at $\delta 4.44$ and one doublet of doublets at $\delta 3.60$ revealing the presence of one esterified and one hydroxylated methine proton, one three-proton singlet at $\delta 1.66$ corresponding to a methyl group on a double bond, and several overlapped signals between $\delta 0.77$ and 2.55. The ${ }^{13} \mathrm{C}$-NMR spectrum showed the presence of two oxygenated carbons $(\delta 76.20,80.53)$, two olefinic carbons, 
Table 1. ${ }^{1} \mathrm{H}-(400 \mathrm{MHz})$ and ${ }^{13} \mathrm{C}-\mathrm{NMR}$ Spectral Data $(50 \mathrm{MHz})$ of $\mathbf{1}-\mathbf{1 2}\left(\mathrm{CDCl}_{3}\right)$

\begin{tabular}{|c|c|c|c|c|c|c|}
\hline \multirow{2}{*}{ Atom } & \multicolumn{3}{|c|}{${ }^{13} \mathrm{C}$} & \multicolumn{3}{|c|}{${ }^{1} \mathrm{H}$} \\
\hline & $2^{a)}$ & $6^{b)}$ & $10^{c)}$ & $2^{a)}$ & $6^{b)}$ & $10^{c)}$ \\
\hline 1 & 38.41 & 38.22 & 38.37 & & & \\
\hline 2 & 23.67 & 23.52 & 23.70 & & & \\
\hline 3 & 80.49 & 80.45 & 80.53 & $\begin{array}{c}4.48 \\
(\mathrm{dd}, J=5.9,10.6)\end{array}$ & $\begin{array}{c}4.50 \\
(\mathrm{dd}, J=7.0,8.8)\end{array}$ & $\begin{array}{c}4.44 \\
(\mathrm{dd}, J=5.8,10.5)\end{array}$ \\
\hline 4 & 37.82 & 37.71 & 37.72 & & & \\
\hline 5 & 55.43 & 55.21 & 55.35 & & & \\
\hline 6 & 18.12 & 18.19 & 18.15 & & & \\
\hline 7 & 33.92 & 32.53 & 34.10 & & & \\
\hline 8 & 39.99 & 39.84 & 40.90 & & & \\
\hline 9 & 49.88 & 46.71 & 49.87 & & & \\
\hline 10 & 36.97 & 37.31 & 37.65 & & & \\
\hline 11 & 21.36 & 23.52 & 20.83 & & & \\
\hline 12 & 25.84 & 122.21 & 24.70 & & $5.24(\mathrm{t}, J=3.7)$ & \\
\hline 13 & 38.70 & 143.49 & 38.37 & & & \\
\hline 14 & 42.31 & 43.74 & 44.09 & & & \\
\hline 15 & 35.98 & 35.51 & 37.19 & & & \\
\hline 16 & 77.33 & 65.97 & 76.20 & $\begin{array}{c}3.39 \\
(\mathrm{dd}, J=4.4,11.7)\end{array}$ & $\begin{array}{c}4.20 \\
(\mathrm{dd} J=5.1,11.4)\end{array}$ & $\begin{array}{c}3.60 \\
(\mathrm{dd}, J=4.5,11.6)\end{array}$ \\
\hline 17 & 40.91 & 36.72 & 43.81 & & & \\
\hline 18 & 47.56 & 49.03 & 47.63 & & & \\
\hline 19 & 39.00 & 46.46 & 47.63 & & & \\
\hline 20 & 153.63 & 30.87 & 149.46 & & & \\
\hline 21 & 24.99 & 34.11 & 29.80 & & & \\
\hline 22 & 35.21 & 30.51 & 37.63 & & & \\
\hline 23 & 27.93 & 28.04 & 27.93 & $0.85(\mathrm{~s})$ & $0.87(\mathrm{~s})$ & $0.81(\mathrm{~s})$ \\
\hline 24 & 16.54 & 16.80 & 15.90 & $0.85(\mathrm{~s})$ & $0.87(\mathrm{~s})$ & $1.01(\mathrm{~s})$ \\
\hline 25 & 16.32 & 15.55 & 16.53 & $0.88(\mathrm{~s})$ & $0.97(\mathrm{~s})$ & $0.82(\mathrm{~s})$ \\
\hline 26 & 16.32 & 16.80 & 16.13 & $1.03(\mathrm{~s})$ & $0.99(\mathrm{~s})$ & $0.84(\mathrm{~s})$ \\
\hline 27 & 15.84 & 27.09 & 16.13 & $0.98(\mathrm{~s})$ & $1.22(\mathrm{~s})$ & $0.96(\mathrm{~s})$ \\
\hline 28 & 12.79 & 21.47 & 11.64 & $0.85(\mathrm{~s})$ & $0.79(\mathrm{~s})$ & $0.77(\mathrm{~s})$ \\
\hline 29 & 25.18 & 33.23 & 109.82 & $1.03(\mathrm{~d}, J=6.2)$ & $0.89(\mathrm{~s})$ & $\begin{array}{l}4.68(\mathrm{~d}, J=2.0) \\
4.57(\mathrm{~d}, J=1.3)\end{array}$ \\
\hline 30 & 107.39 & 23.93 & 19.25 & $\begin{array}{l}4.63(\mathrm{t}, J=2.0) \\
4.65(\mathrm{t}, J=2.0)\end{array}$ & $0.91(\mathrm{~s})$ & $1.66(\mathrm{~s})$ \\
\hline & & & & Fatty acid moiety & & \\
\hline $\mathrm{CH}_{2} \mathrm{COO}-$ & 34.84 & 34.84 & 34.84 & $2.29(\mathrm{t}, J=7.3)$ & $2.29(\mathrm{t}, J=7.0)$ & $2.29(\mathrm{t}, J=7.0)$ \\
\hline$\stackrel{\mathrm{COO}-}{-}$ & 173.73 & 173.73 & 173.74 & & & \\
\hline $\mathrm{CH}_{2}$ & 31.90 & 31.90 & 31.90 & & & \\
\hline $\mathrm{CH}_{2}$ & 26.90 & 26.91 & 26.90 & & & \\
\hline $\mathrm{CH}_{2}$ & 22.68 & 22.68 & 22.67 & & & \\
\hline$\left(\mathrm{CH}_{2}\right)_{n}$ & $29.26-29.66$ & $29.25-29.65$ & $29.25-29.65$ & 1.25 (brs) & $1.25(\mathrm{brs})$ & 1.25 (br s) \\
\hline $\mathrm{CH}_{2}$ & 25.16 & 25.17 & 25.14 & & & \\
\hline $\mathrm{CH}_{3}$ & 14.12 & 14.12 & 14.11 & $0.88(\mathrm{t}, J=7.0)$ & $0.88(\mathrm{t}, J=7.0)$ & $0.87(\mathrm{t}, J=7.0)$ \\
\hline
\end{tabular}

a) Compounds 1, 3 and $\mathbf{4}$ showed similar NMR data to that of $\mathbf{2}$ except for the alkyl chain moiety of the fatty acid residue. b) Compounds $\mathbf{5}, \mathbf{7}$ and $\mathbf{8}$ showed similar NMR data to that of $\mathbf{6}$ except for the alkyl chain moiety of the fatty acid residue. c) Compounds $\mathbf{9 , 1 1}$ and $\mathbf{1 2}$ showed similar NMR data to that of $\mathbf{1 0}$ except for the alkyl chain moiety of the fatty acid residue.

one esteric carbonyl and several aliphatic carbons. Alkaline hydrolysis afforded a triterpene diol and a fatty acid, identified as palmitic acid with the method described above. The triterpene diol was identified as $16 \beta$-hydroxylupeol by interpretation of its MS and NMR spectra and by comparison with the reported spectroscopic data. ${ }^{12,13)}$

In addition, compounds $\mathbf{9 , 1 1}$ and $\mathbf{1 2}$ were isolated from the combined fractions adjacent to 10. After hydrolysis of the fractions and esterification, $16 \beta$-hydroxylupeol and the fatty acids myristic acid, palmitic acid, stearic acid and eicosanoic acid were identified.

Among the above described constituents, the stearic and eicosanoic acid esters of arnidiol $(3,4)$, and $16 \beta$-hydroxylupeol $(\mathbf{1 1}, \mathbf{1 2})$, and the eicosanoic ester of maniladiol $(\mathbf{8})$ are new natural products. All the other corresponding esters had been described only with ${ }^{1} \mathrm{H}-\mathrm{NMR},{ }^{14-16)}$ and their

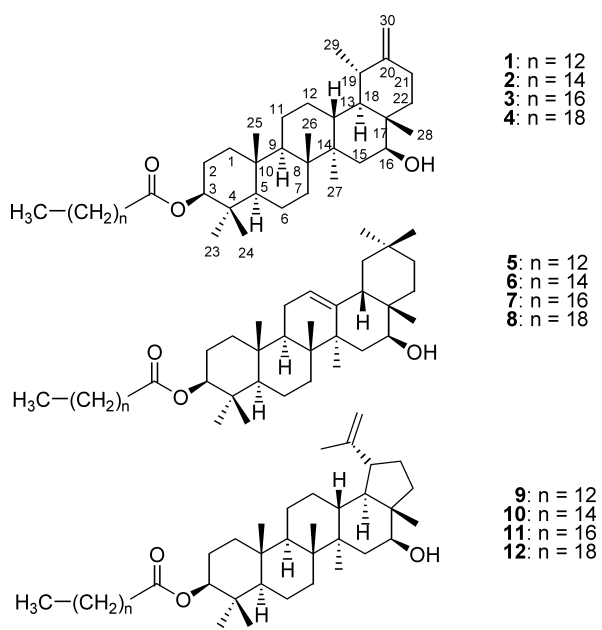


detailed ${ }^{13} \mathrm{C}$-NMR spectra is reported herein for the first time (Table 1).

Finally, investigation of the combined methanol and 50\% methanol extracts led to the isolation of 4 major constituents: pinoresinol- $\beta$-D-glucoside ${ }^{17)}$ rutin, ${ }^{18)} 3,4-O$-dicaffeoyl quinic acid $^{19)}$ and cinnamic acid. ${ }^{20)}$

The identification of 3,4-dicaffeoylquinic acid (inhibitor of 5 -lipooxigenase $)^{21)}$ and rutin (an inhibitor of edema in carrageneen rat paw edema test $)^{22,23)}$ may explain the previously reported anti-inflammatory activity of the methanol extract. ${ }^{6}$ ) Additionally, the similarity of the isolated triterpene diol fatty acid esters from the less polar extracts with the active constituents of Calendula officinalis ${ }^{24,25)}$ may support the traditional anti-inflammatory use of the plant.

\section{Experimental}

General Experimental Procedures Optical rotations were measured with a Perkin-Elmer 341 polarimeter. IR spectra were taken on a PerkinElmer Paragon 500 instrument. NMR spectra were recorded on a Bruker DRX400, ${ }^{1} \mathrm{H}-\mathrm{NMR}(400 \mathrm{MHz})$ and a Bruker AC200, ${ }^{13} \mathrm{C}-\mathrm{NMR}(50 \mathrm{MHz})$ Chemical shifts are given in $\delta$ values with tetramethylsilane (TMS) as an internal standard. Coupling constants $(J)$ are given in $\mathrm{Hz}$. The signals of ${ }^{1} \mathrm{H}$ and ${ }^{13} \mathrm{C}$ spectra were unambiguously assigned using 2D NMR techniques: correlation spectroscopy (COSY), heteronuclear multiquantum correlation (HMQC), HMQC-TOCSY and HMBC experiments. High resolution MS were obtained on an AEI MS-902 mass spectrometer. Column chromatography was conducted using flash Si gel 60 Merck $(40-63 \mu \mathrm{m})$, with an overpressure of 300 mbar. Medium pressure liquid chromatography (MPLC) was performed with a Büchi model 688 apparatus on columns containing Si gel 60 Merck $(20-40 \mu \mathrm{m})$ or R18 Si gel 60 Merck $(20-40 \mu \mathrm{m})$. Reversed phase high performance liquid chromatography (RP-HPLC) was performed with a Thermo Finnigan Spectra system on a Supelcosil R-18 $5 \mu \mathrm{m}$ column $\left(25 \mathrm{~cm} \times 10 \mathrm{~mm}\right.$ i.d.) with $\mathrm{MeOH}(4 \mathrm{ml} / \mathrm{min})$ as a mobile phase at $25^{\circ} \mathrm{C}$, according to a previously described method. ${ }^{15)}$

Plant Material The plant material was collected in July 2000 on Mount Ošljak (south Serbia). A voucher specimen is preserved in the Institute of Botany Herbarium, Botanical Garden, University of Belgrade (BEOU, No. 8402).

Extraction and Isolation The dried aerial parts of Achillea alexandriregis $(280 \mathrm{~g})$ were rinsed with acetone to remove the resin from the surface of leaves, stems and flowers. Then, the plant material was dried, ground into powder and extracted on a Soxhlet apparatus with petroleum ether, toluene, chloroform, ethylacetate, methanol and $50 \%$ methanol. The solvents were evaporated under reduced pressure at $40^{\circ} \mathrm{C}$. Chloroform and ethylacetate extracts were combined, as well as methanol and 50\% methanol extracts, and submitted to chromatographic separations. After evaporation of the solvent from the combined chloroform and ethyl acetate extracts, the residue $(2.8 \mathrm{~g})$ was submitted to silica gel column chromatography containing Si gel 60 Merck $(20-40 \mu \mathrm{m})$ with cyclohexane : $\mathrm{CH}_{2} \mathrm{Cl}_{2}$ (from 100:0 to $20: 80$ gradient) to afford 167 fractions: frs. $1-9$, cyclohexane: $\mathrm{CH}_{2} \mathrm{Cl}_{2}(90: 10)$ eluate; frs. $10-19$, cyclohexane : $\mathrm{CH}_{2} \mathrm{Cl}_{2}$ (70:30) eluate; frs. $20-75$, cyclohexane : $\mathrm{CH}_{2} \mathrm{Cl}_{2}(50: 50)$ eluate; and frs. 76-167 cyclohexane: $\mathrm{CH}_{2} \mathrm{Cl}_{2}$ $(20: 80)$ eluate. Fractions $36-46$ were submitted to preparative TLC to afford the mixture of $\alpha$-amyrin and $\beta$-amyrin $(6 \mathrm{mg})$. Fractions $86-90$ afforded compound 6 (6 mg), while the combined adjacent fractions $80-85$, 86 - 90 and 91-97 afforded a mixture of maniladiol fatty acid esters $\mathbf{5}-\mathbf{8}$ which were purified by prep. HPLC to give each compound in pure state, $5(2.1 \mathrm{mg}), 6(1.6 \mathrm{mg}), 7(2.3 \mathrm{mg})$ and $8(2.0 \mathrm{mg})$. Fractions $109-110$ afforded compound 2 (7 mg), while the combined fractions 104-108, $109-110$ and $111-115$ afforded the mixture of arnidiol fatty acid esters 1-4 which were purified by prep. HPLC to afford: 1 (3.5 mg), $2(5.0 \mathrm{mg})$, $3(6.1 \mathrm{mg})$ and $4(3.4 \mathrm{mg})$. Fractions $113-132$ were submitted to preparative TLC to give $\beta$-sitosterol ( $7 \mathrm{mg}$ ), and fractions 136 - 138 afforded compound $10(3 \mathrm{mg})$. Finally, the combined adjacent fractions $133-135,136-138$ and 139-141 afforded a mixture of $16 \beta$-hydroxylupeol fatty acid esters $\mathbf{9}-\mathbf{1 2}$ which were purified by prep. HPLC to afford: $9(1.9 \mathrm{mg}), \mathbf{1 0}(1.0 \mathrm{mg})$, $11(2.1 \mathrm{mg})$ and $12(2.0 \mathrm{mg})$. Evaporation of the combined methanol extracts afforded a residue ( $32 \mathrm{~g}$ ) which was submitted to R-18 column chromatography using water-methanol (from $100: 0$ to $0: 100$ gradient) to give 11 fractions. Fraction $5(2.14 \mathrm{~g})$ was submitted to silica gel column chromatography with $\mathrm{CH}_{2} \mathrm{Cl}_{2}: \mathrm{MeOH}$ (from $98: 2$ to $80: 20$ gradient) to afford 85 fractions
Fractions $46-47$ afforded pinoresinol- $\beta$-D-glucoside $(35 \mathrm{mg})$, fractions $49-51$ afforded cinnamic acid, fractions $76-78$ afforded rutin $(10 \mathrm{mg})$ and fractions $82-83$ afforded 3,4-dicaffeoyl-quinic acid (48 $\mathrm{mg})$.

Arnidiol 3-O-Stearate (3): $\mathrm{mp} 83-84^{\circ} \mathrm{C} ;[\alpha]_{\mathrm{D}}+45.2^{\circ}\left(c=0.1, \mathrm{CHCl}_{3}\right)$; IR $\left(\mathrm{CHCl}_{3}\right) \mathrm{cm}^{-1}: 3380,1725,1440,1260 ;{ }^{1} \mathrm{H}-,{ }^{13} \mathrm{C}-\mathrm{NMR}$ see Table 1 ; HREI-MS: Calcd for $\mathrm{C}_{48} \mathrm{H}_{84} \mathrm{O}_{3}\left(\mathrm{M}^{+}\right)$: 708.6420. Found 708.6425.

Arnidiol 3-O-Eicosanoate (4): $\mathrm{mp} 83-84^{\circ} \mathrm{C} ;[\alpha]_{\mathrm{D}}+44.3^{\circ} \quad(c=0.1$, $\left.\mathrm{CHCl}_{3}\right)$; IR $\left(\mathrm{CHCl}_{3}\right) \mathrm{cm}^{-1}: 3380,1725,1440,1265 ;{ }^{1} \mathrm{H}-,{ }^{13} \mathrm{C}-\mathrm{NMR}$ see Table 1; HR-EI-MS: Calcd for $\mathrm{C}_{50} \mathrm{H}_{88} \mathrm{O}_{3}\left(\mathrm{M}^{+}\right)$: 736.6733. Found 736.6729.

Maniladiol 3-O-Eicosanoate (8): mp 93-94 ${ }^{\circ} \mathrm{C} ;[\alpha]_{\mathrm{D}}+39.2^{\circ}(c=0.1$, $\left.\mathrm{CHCl}_{3}\right)$; IR $\left(\mathrm{CHCl}_{3}\right) \mathrm{cm}^{-1}: 3370,1720,1450,1245 ;{ }^{1} \mathrm{H}-,{ }^{13} \mathrm{C}-\mathrm{NMR}$ see Table 1; HR-EI-MS: Calcd for $\mathrm{C}_{50} \mathrm{H}_{88} \mathrm{O}_{3}\left(\mathrm{M}^{+}\right)$: 736.6733. Found 736.6731.

16 $\beta$-Hydroxylupeol 3 - $O$-Stearate $(\mathbf{1 1}): \mathrm{mp} 90-91^{\circ} \mathrm{C} ;[\alpha]_{\mathrm{D}}+33.2^{\circ}$ $\left(c=0.1, \mathrm{CHCl}_{3}\right)$; IR $\left(\mathrm{CHCl}_{3}\right) \mathrm{cm}^{-1}: 3410,1730,1640,1465,1245 ;{ }^{1} \mathrm{H}-,{ }^{13} \mathrm{C}-$ NMR see Table 1; HR-EI-MS: Calcd for $\mathrm{C}_{48} \mathrm{H}_{84} \mathrm{O}_{3}\left(\mathrm{M}^{+}\right)$: 708.6420. Found 708.6418

16 $\beta$-Hydroxylupeol 3-O-Eicosanoate $(12): \operatorname{mp~} 90-91{ }^{\circ} \mathrm{C} ;[\alpha]_{\mathrm{D}}+31.2^{\circ}$ $\left(c=0.1, \mathrm{CHCl}_{3}\right)$; IR $\left(\mathrm{CHCl}_{3}\right) \mathrm{cm}^{-1}: 3410,1731,1640,1465,1248 ;{ }^{1} \mathrm{H}-,{ }^{13} \mathrm{C}-$ NMR see Table 1; HR-EI-MS: Calcd for $\mathrm{C}_{50} \mathrm{H}_{88} \mathrm{O}_{3}\left(\mathrm{M}^{+}\right)$: 736.6733. Found 736.6727

Hydrolysis of Fatty Acid Esters Hydrolysis of the fatty acid esters of the mixtures of triterpenes (each $10 \mathrm{mg}$ ) was performed with $5 \% \mathrm{KOH}$ in $\mathrm{MeOH}(15 \mathrm{ml})$ under reflux for $2 \mathrm{~h}$. Methyl ester derivatives of fatty acids were prepared by refluxing fatty acids with $1 \% \mathrm{H}_{2} \mathrm{SO}_{4}$ in methanol $(15 \mathrm{ml})$ for $1 \mathrm{~h}$. The methyl ester mixture was analyzed with GC-MS. The triterpene diol in each case was purified by preparative TLC with $\mathrm{CH}_{2} \mathrm{Cl}_{2} / \mathrm{MeOH}$ $99: 1$.

Gas Chromatography-Mass Spectrometry The GC-MS analyses were carried out using a Hewlett Packard 6890-5973 GC-MS system operating on Electron Impact mode (equipped with a HP $5 \mathrm{MS} 30 \mathrm{~m} \times 0.25 \mathrm{~mm}, 0.25 \mu \mathrm{m}$ film thickness capillary column). He $(2 \mathrm{ml} / \mathrm{min})$ was used as carrier gas. The initial temperature of the column was $60^{\circ} \mathrm{C}$, and then it was heated to $280^{\circ} \mathrm{C}$ at a rate of $3{ }^{\circ} \mathrm{C} / \mathrm{min}$. The identification of the fatty acid esters was based on comparison of their EI-mass spectra with the NIST/NBS, Wiley library spectra.

\section{References}

1) Brandley P., "British Herbal Compendium," Vol. 1, British Herbal Medicine Association, Dorset, 1992, pp. 227-229.

2) Blumenthal M., "The Complete German Commission E Monographs, Therapeutic Guide to Herbal Medicines," American Botanical Council, Austin, Texas, 1998, pp. 233-234.

3) Glasl A., Mucaji P., Werner I., Presser A., Jurenitsch J., Z. Naturforsch., 57c, 976-982 (2002).

4) Gajic M., Asteraceae Dumortier in: Josifovic M. et al., Flora SR Srbije, VII, SANU, Odeljenje prirodno-matematičkih nauka, Beograd, 1976, pp. 102-103.

5) Kundakovic T., Mimica-Dukic N., Markovic D., Kovacevic N., Arch. Pharm., Serbian Pharmaceutical Society, 48, 950-951 (1998).

6) Kundakovic T., Dobric S., Bokonjic D., Dragojevic-Simic V., Kilibarda V., Kovacevic N., Pharmazie, 55, 866-867 (2000).

7) Ristic M., Kovacevic N., Tasic S., Menkovic N., Grubišic D., Djokovic D., 44th Annual Congress of the Society for Medicinal Plant Research and a Joint Meeting with the Czech Biotechnology Society, Prague, on 3-7 September, 1996, p. 211.

8) Agrawal P. K., Jain D. C., "Progress in NMR Spectroscopy," Vol. 24, Pergamon Press, Oxford, 1992, pp. 1-90.

9) Furuya T., Orihara Y., Hayashi C., Phytochemistry, 26, 715-720 (1987).

10) Pyrok J., Baranowska E., Tetrahedron Lett., 14, 809-810 (1973).

11) Quijano L., Rios T., Fronczek F., Fischer N., Phytochemistry, 49, 2065-2068 (1998).

12) Yuruker A., Orjala J., Sticher O., Rali T., Phytochemistry, 48, 863866 (1998).

13) Wenkert E., Baddeley G. V., Burfitt I. R., Moreno L. N., Org. Mag. Reson., 11, 337-343 (1978).

14) Oksuz S., Topcu G., Phytochemistry, 26, 3082-3084 (1987).

15) Ukiya M., Akihisa T., Yasukawa K., Kasahara Y., Kimura Y., Koike K., Nikaido T., Takido M., J. Agric. Food Chem., 49, 3187-3197 (2001).

16) Torres P., Chinchilla R., Grande M., Studia Chemica, 17, 53-57 (1992).

17) Klimek B., Tokar M., Acta Pol. Pharm., 55, 499-504 (1998).

18) Vasange M., Liu B., Welch C., Rolfsen W., Bohlin L., Planta Med., 63, 
$511-517$ (1997).

19) Hennessy D., Hook I., Sheridan H., McGee A., Phytochemistry, 28, 489-490 (1989).

20) Cristau H. J., Taillefer M., Tetrahedron, 54, 1507-1522 (1988).

21) Nishizawa M., Izuhara R., Kaneko K., Koshihara Y., Fujimoto Y., Chem. Pharm. Bull., 36, 87-95 (1988).

22) Guardia T., Rotelli A. E., Juarez A. O., Pelzer L. E., Farmaco, 56, $683-687$ (2001)
23) Pelzer L. E., Guardia T., Juarez A. O., Guerreiro E., Farmaco, 53, 421-424 (1998).

24) Della Loggia R., Tubaro A., Sosa S., Becker H., Saar S., Isaac O., Planta Med., 60, 516-520 (1994).

25) Zitterl-Englseer K., Sosa S., Jurenitsch J., Schubert-Zsilaveez M., Della Loggia R., Tubaro A., Bertoldi M., Franz C., J. Ethnopharmacol., 57, 139-144 (1997). 